\title{
SPATIOTEMPORAL SEQUENCING PROCESSES OF PEDESTRIANS IN URBAN RETAIL ENVIRONMENTS
}

\author{
Xavier van der Hagen \\ Aloys Borgers \\ Harry Timmermans \\ Faculty of Architecture, Building, and Planning \\ University of Technology \\ Post Office Box 513, 5600 MB Eindhoven \\ The Netherlands
}

\begin{abstract}
In this article, the authors determine the extent to which several decision heuristics are present in pedestrians' spatial shopping behavior in downtown retail environments. Two factors, length of the observed route and observed sequence in which destinations are visited, were used to define temporal heuristics. Further, two spatial heuristics were investigated: the tendency of some pedestrians to choose first the destination farthest away from the point they entered the city center and the tendency of others to choose first the destination closest to their entry point. Empirical analysis demonstrated that only a small proportion of the pedestrians reveals optimal choice behavior.
\end{abstract}

\section{INTRODUCTION}

Theories and models of consumer spatial choice behavior have changed dramatically over the past few years. About a decade ago, most researchers interested in destination and route choice behavior conceptualized these choice processes as problems of single choice. Their research effort typically involved predicting the probability that a single destination or route would be chosen to conduct a particular activity as a function of the attributes of the destination or route, and, possibly, of some personal characteristics of the traveler. They assumed that choice behavior was the result of a decision-making process by which individuals integrated their utilities associated with the attributes of a choice alternative according to some algebraic rule into an overall utility and then chose the alternative with the highest overall utility value.

It has been increasingly shown, however, that such single-purpose trips constitute only a small proportion of everyday travel. Over the years, the importance of multipurpose trips has received widespread recognition (Hanson 1980a). In addition, the theoretical underpinnings of discrete choice theory have been questioned. For example, Hanson (1980b) has convincingly argued that the classical axioms underlying discrete choice models (single-choice axiom; single-purpose trip axiom; independence axiom; separability axiom and the stable-utility-function axiom) are at variance with empirical observations. This has confronted transportation researchers with new challenges, because multi1989.

An earlier version of this paper was presented at the 11th Pacific Conference, Singapore, July 
stop-multipurpose behavior is a much more complex kind of behavior. Researchers should take into account the number of stops made, the choice of destinations visited, and the sequencing of destinations, both in space and time, within the entire journey.

An ever-recurring question in this line of research concerns the spatiotemporal sequencing of destination choices. A fundamental issue in the analysis of multistop behavior is to understand the decision heuristics individuals use when they are faced with the problem of organizing a journey that involves two or more destinations. In this article we seek to determine the extent to which different decision heuristics are present in pedestrians' spatial shopping behavior in downtown retail environments. To accomplish this objective, we first discuss some heuristics that potentially can be applied to the problem of multistopmultipurpose trips. We continue with a description of the study area and the survey, followed by the results of the analyses and a number of concluding comments.

\section{RESEARCH QUESTIONS}

The problem of multistop-multipurpose behavior can be viewed as a problem of choosing and sequencing $m$ different destinations to conduct $k$ different activities or buy $k$ different goods. There are several different decision heuristics that an individual might adopt to deal with this problem. To simplify the problem, let us first assume that the nonlocational attributes (attractiveness) of the destinations are not taken into account. This implies that some distance metric is the only determinant of an individual's choice behavior. Even for this simple problem there are several different decision heuristics that an individual might adopt to organize the journey. The decision heuristic might be distance driven. This would imply that an individual's behavior is not based on some a priori sequence of trip purposes, but rather on the spatial configuration of land uses. A rational traveler would select that destination closest to home that allows fulfillment of one of the purposes. In the following segment of the journey, a second destination is sought closest to the one chosen at the previous stop. This process continues until all purposes have been satisfied.

The problem becomes slightly more complex if we introduce a given set of destinations that has to be patronized. This set might be the result of a previous decision-making process in which an individual has decided which destinations to patronize, or might be the result of a purpose-sequence-driven process. In the latter case, the problem differs from the one previously discussed in that an order constraint is imposed on the journey. In this case, an individual might minimize the distance traveled on each segment of the journey. This is an example of a sequential decision-making process. The problem of multistopmultipurpose behavior is broken down into a sequence of single choices. Since we have made the simplifying assumption that the nonlocational attributes are irrelevant, an individual engaged in sequential decision making attempts to minimize distance between all successive pairs of destinations that make up the entire journey. We will call this a local-distance-minimizing ( $L-D-M)$ heuristic. Alternatively, the traveler could choose destinations in such an order that the total distance traveled on the entire journey is minimized. This is an example 
of a simultaneous decision-making process in the sense that an individual attempts to minimize the total distance traveled. We will call this a total-distanceminimizing (T-D-M) heuristic. Mathematically, this heuristic is equivalent to the traveling salesman problem: in what order should a salesman located in a given city, who wishes to visit $n$ cities once and only once, visit these cities so as to minimize the total distance traveled?

It should be noted that in some empirical situations one cannot discriminate between the two heuristics. This will be the case when the route that results from applying the L-D-M heuristic is identical to the shortest route. Actually, two factors determine the degree by which individuals deviate from or are engaged in some form of rational behavior: distance itself, and the sequence in which destinations are visited. Individuals may still patronize the destinations in an optimal order, without minimizing distance in all segments of their trip. We call this a global-distance-minimizing (G-D-M) heuristic (see Table 1).

The above heuristics concern the temporal sequencing of destinations in a multistop-multipurpose trip. However, temporally based heuristics sometimes generate sequences of destinations that are equivalent on the objective function. This is especially true for symmetrical tours. The total distance traveled in the sequence $\mathrm{H}-\mathrm{A}-\mathrm{B}-\mathrm{C}-\mathrm{D}-\mathrm{H}$ is exactly the same as the total distance traveled in the sequence $\mathrm{H}-\mathrm{D}-\mathrm{C}-\mathrm{B}-\mathrm{A}-\mathrm{H}$, where $\mathrm{H}$ is home or the entry/departure point of some area. Hence, some additional assumptions have to be made if we wish to identify the heuristics underlying multistop-multipurpose travel. In particular, the spatial sequencing needs investigation. Individuals may visit destinations in order of proximity to home or entry point. We will call this a nearest-destinationoriented $(N-D-O)$ heuristic. It implies that individuals will generally have to carry the things they buy along the route across longer distances. Alternatively an individual may decide to visit first the destination farthest from home or entry point. We will call this a farthest-destination-oriented ( $F-D-O)$ heuristic.

The empirical evidence to support any of the above decision heuristics is very limited and not very conclusive. For example, Hayes-Roth and Hayes-Roth (1979), working with a computational process model, examined the heuristics individuals use when they are asked to plan a trip. Their subjects had to choose the order in which to visit a given set of destinations to conduct a series of activities. Their computer simulations suggested that the subjects used a combination of the L-D-M and N-D-O heuristics: they first chose the destination closest to home or entry point, then the destination closest to the one chosen at the previous step, and so on until all activities were conducted. This finding was elaborated in a series of studies conducted by Gärling and his associates. Säisä and Gärling (1987) found, both in a laboratory setting and in real-world environments, that individuals tend to use the G-D-M heuristic rather than the L-D-M heuristic when the latter would result in a substantially longer distance required to complete the tour. In two other projects (Gärling et al. 1986; Gärling 1987) they found that the choice between these two heuristics is dependent upon the cognitive representation of the environment. If individuals possess some maplike mental representation of the environment, they are able to apply the G-D-M heuristic; otherwise they tend to minimize distance locally in a sequential decision-making process. 
TABLE 1. Types of Temporal Heuristics

\author{
Distances \\ All Segments \\ Minimized \\ All Segments \\ Not Minimized
}

Sequence of Destinations

Nonoptimal
Local-Distance-Minimizing
Heuristic (L-D-M)
Mixed
Heuristic

Optimal
Total-Distance-Minimizing
Heuristic (T-D-M)
Global-Distance-
Minimizing Heuristic
(G-D-M)
(G-D-M)

In yet another study, Gärling and Gärling (1988) did not request their subjects to minimize distance, but examined their actual behavior, allowing them to investigate the importance of distance-minimizing behavior. They concluded that some kind of distance-minimizing behavior appeared to be an important goal of pedestrian shoppers and that the most frequently observed behavior involved a combination of what we have called an F-D-O heuristic and an L-D-M heuristic: individuals tend to choose first the destination farthest away from their entry point and then minimize distance locally back to the point where they entered the city center.

All of the studies cited above concerned shopping trips. O'Kelly and Miller (1984) investigated the characteristics of more-general multistop-multipurpose behavior involving many types of activities. They found that the percentage of their respondents displaying global distance-minimizing behavior decreased substantially with increasing trip length. They also found that the probability of choosing minimum paths increased when the degree of difference between the minimum and maximum path times increased. As far as the spatial structuring of the trip is concerned, there were almost equal proportions of respondents who stopped first at the closest destination and respondents who stopped first at the destination farthest from home.

This examination of the literature suggests scattered pieces of empirical knowledge pertaining to various kinds of travel and different theoretical concepts. The objective of the present study is to replicate and elaborate previous work in an attempt to systematically uncover the use of different decision heuristics in the context of pedestrian spatial shopping behavior in downtown retail environments. The following research questions guided the analyses:

(a) To what degree do shopping pedestrians reveal local-distance-minimizing behavior?

(b) To what extent do shopping pedestrians exhibit simultaneous decision making as evidenced by a total-distance-minimizing heuristic?

(c) To what extent are shopping pedestrians involved in global-distance-minimizing behavior?

(d) To what degree do shopping pedestrians reveal nearest-destination-oriented behavior?

(e) To what degree do shopping pedestrians display farthest-destinationoriented behavior?

(f) Is there any association between temporal and spatial sequencing heuristics, and if so, what is the nature of this association? 
TABLE 2. Number of Shopping Pedestrians Applying Different Temporal Decision Heuristics

\begin{tabular}{|c|c|c|c|c|c|c|c|c|}
\hline \multirow[b]{3}{*}{ Heuristic } & \multicolumn{4}{|c|}{ Maastricht } & \multicolumn{4}{|c|}{ Eindhoven } \\
\hline & \multicolumn{2}{|c|}{ Planned } & \multicolumn{2}{|c|}{ Unplanned } & \multicolumn{2}{|c|}{ Planned } & \multicolumn{2}{|c|}{ Unplanned } \\
\hline & Absolute & Rel. (\%) & Absolute & Rel. (\%) & Absolute & Rel. (\%) & $\overline{\text { Absolute }}$ & Rel. (\%) \\
\hline $\begin{array}{l}\text { L-D-M } \\
\text { T-D-M } \\
\text { G-D-M } \\
\text { Other }\end{array}$ & $\begin{array}{r}23 \\
54 \\
164 \\
194\end{array}$ & $\begin{array}{r}5 \\
12 \\
38 \\
45\end{array}$ & $\begin{array}{r}9 \\
8 \\
131 \\
151\end{array}$ & $\begin{array}{r}3 \\
3 \\
44 \\
50\end{array}$ & $\begin{array}{r}21 \\
64 \\
160 \\
65\end{array}$ & $\begin{array}{r}7 \\
20 \\
52 \\
21\end{array}$ & $\begin{array}{r}5 \\
26 \\
165 \\
76\end{array}$ & $\begin{array}{r}2 \\
10 \\
60 \\
28\end{array}$ \\
\hline Total & 435 & 100 & 299 & 100 & 310 & 100 & 272 & 100 \\
\hline
\end{tabular}

(g) Does the propensity to choose a local-distance-minimizing heuristic differ systematically in terms of the number of stops made during the trip?

(h) Does the propensity to choose a farthest-destination-oriented heuristic differ systematically in terms of the number of stops made during the trip?

(i) To what degree do the answers to the above questions depend upon whether the trip is planned or unplanned?

(j) To what degree do the answers to the above questions depend upon the layout of the retail environment?

Before we discuss the results of the analyses, it is important to emphasize the context and limitations of the present study. So far, we have assumed that the nonlocational attributes are irrelevant in the choice process. If we allow these attributes to enter the choice process, the problem instantly becomes far more complex in the sense that distance should be replaced by a more general utility function. The complexity of the research problem further increases if we allow impulse choices to occur. This article is part of a wider project that ultimately attempts to develop and test a model for this more general problem. However, in this article we are only interested in the spatiotemporal sequencing of destinations. That is, we assume the destinations that are visited by the sample respondents are given. The results of this study thus provide only limited, albeit important, evidence on the prevalence of decision heuristics underlying multistop-multipurpose travel.

\section{DATA COLLECTION}

The extent to which these different decision heuristics are present in multistop-multipurpose behavior was studied in the context of pedestrian movement in inner-city shopping areas. As Hanson (1979) has argued, pedestrian movement constitutes one of the most important types of multipurpose behavior. The data were collected for the cities of Maastricht, located in the southern Netherlands, and Eindhoven, located a little farther to the north. Maastricht is a historical city. This is evidenced in the general layout of the city center, which is characterized by several small and winding streets. In contrast, Eindhoven is a modern city with a basically rectangular street pattern in the city center. This layout dates from the late 1940s, after the bombing of the city in World War II.

The data were collected in the autumn of 1987, on a Thursday and a Saturday from 10 A.M. to 5 P.M. Shops in the Netherlands open at 9 A.M. and 
TABLE 3. Number of Shopping Pedestrians Applying Different Spatial Decision Heuristics

\begin{tabular}{|c|c|c|c|c|c|c|c|c|}
\hline \multirow[b]{3}{*}{ Heuristic } & \multicolumn{4}{|c|}{ Maastricht } & \multicolumn{4}{|c|}{ Eindhoven } \\
\hline & \multicolumn{2}{|c|}{ Planned } & \multicolumn{2}{|c|}{ Unplanned } & \multicolumn{2}{|c|}{ Planned } & \multicolumn{2}{|c|}{ Unplanned } \\
\hline & Absolute & Rel. (\%) & Absolute & Rel. (\%) & Absolute & Rel. (\%) & Absolute & Rel. (\%) \\
\hline $\begin{array}{l}\text { N-D-O } \\
\text { F-D-O } \\
\text { Neutral }\end{array}$ & $\begin{array}{r}99 \\
302 \\
34\end{array}$ & $\begin{array}{r}22.8 \\
69.4 \\
7.8\end{array}$ & $\begin{array}{r}83 \\
188 \\
28\end{array}$ & $\begin{array}{r}27.8 \\
62.9 \\
9.3\end{array}$ & $\begin{array}{r}148 \\
134 \\
28\end{array}$ & $\begin{array}{r}47.8 \\
43.2 \\
9.0\end{array}$ & $\begin{array}{r}143 \\
109 \\
20\end{array}$ & $\begin{array}{r}52.7 \\
40.0 \\
7.3\end{array}$ \\
\hline Total & 435 & 100.0 & 299 & 100.0 & 310 & 100.0 & 272 & 100.0 \\
\hline
\end{tabular}

close at 6 P.M. on weekdays and 5 P.M. on Saturdays. Data were also collected the one night the shops are allowed to stay open until 9 P.M. Weather conditions were generally fine; hence we have no reason to believe that weather might have affected the results of the present study. For each of the two city centers, a number of entry points were selected in such a way that all entry/departure points were covered. Maastricht contained 16 entry points; Eindhoven had 10. At each point, pedestrians who had completed their shopping in the downtown area were randomly selected and invited to complete a questionnaire about their shopping. The analysis required data on the sequence of shops that were patronized and the routes the pedestrians had taken on the various segments of their journey.

There has been some debate on how such data can be collected most reliably (e.g., Shepherd and Thomas 1980). It has been argued that even if shoppers are interviewed immediately after completing a shopping trip, their report is often flawed through the omission or missequencing of events. However, direct observation of detailed shopping behavior is also fraught with difficulties. It is far more laborious, there are some ethical objections, and finally, some aspects of behavior may be difficult to capture. Hill (1984) compared these two procedures and found that retrospective self-reports are as accurate as unobtrusive observations. Therefore, we decided to use this measurement procedure. Respondents were asked to name, in sequence, the shops they had visited, whether they had planned to visit the shops, and whether they had planned to buy goods in these shops. In addition, the respondents were shown a map of the downtown area and asked to draw on that map the route they had followed to visit the various shops.

\section{ANALYSES AND RESULTS}

Before discussing the results of the analyses, it is important first to explicate how the different decision heuristics were identified. The L-D-M heuristic relates to distance-minimizing behavior between pairs of successive destinations in a trip sequence. Shortest routes between successive destinations in a pedestrian's trip sequence were identified using a shortest-route algorithm, and a pedestrian was said to apply the L-D-M heuristic if his/her self-reported route choice between all successive pairs of destinations coincided with the calculated shortest route. The G-D-M heuristic pertains to the optimal sequence of selected destinations. To identify the pedestrians applying this heuristic, the shortest total distance associated with all possible permutations of the selected desti- 
TABLE 4. Association between Temporal and Spatial Decision Heuristics

\begin{tabular}{|c|c|c|c|c|c|c|}
\hline \multirow[b]{2}{*}{ Heuristic } & \multicolumn{3}{|c|}{ Planned } & \multicolumn{3}{|c|}{ Unplanned } \\
\hline & N-D-O & F-D-O & Neutral & $\mathrm{N}-\mathrm{D}-\mathrm{O}$ & F-D-O & $\overline{\text { Neutral }}$ \\
\hline $\begin{array}{l}\text { L-D-M } \\
\text { T-D-M } \\
\text { G-D-M } \\
\text { Other }\end{array}$ & $\begin{array}{l}17.4 \\
18.5 \\
26.8 \\
21.1\end{array}$ & $\begin{array}{l}78.3 \\
75.9 \\
64.7 \\
70.7\end{array}$ & $\begin{array}{l}\text { MA } \\
4.3 \\
5.6 \\
8.5 \\
8.2\end{array}$ & $\begin{array}{r}\text { CHT } \\
44.4 \\
25.0 \\
28.2 \\
26.5\end{array}$ & $\begin{array}{l}55.6 \\
62.5 \\
60.3 \\
65.6\end{array}$ & $\begin{array}{r}\overline{12.5} \\
11.5 \\
7.9\end{array}$ \\
\hline & \multicolumn{6}{|c|}{ EINDHOVEN } \\
\hline $\begin{array}{l}\text { L-D-M } \\
\text { T-D-M } \\
\text { G-D-M } \\
\text { Other }\end{array}$ & $\begin{array}{l}47.6 \\
45.3 \\
45.6 \\
55.4\end{array}$ & $\begin{array}{l}42.9 \\
42.2 \\
46.9 \\
35.4\end{array}$ & $\begin{array}{r}9.5 \\
12.5 \\
7.5 \\
9.2\end{array}$ & $\begin{array}{l}\overline{53.8} \\
53.3 \\
53.0\end{array}$ & $\begin{array}{l}60.0 \\
42.3 \\
39.4 \\
39.5\end{array}$ & $\begin{array}{r}40.0 \\
3.8 \\
7.3 \\
6.6\end{array}$ \\
\hline
\end{tabular}

nations was calculated. A pedestrian was said to have applied the G-D-M heuristic if the observed sequence of visited destinations was associated with the shortest distance. If the total shortest distance calculated from the selfreported route was identical to the solution of the traveling salesman problem, the pedestrian was said to exhibit T-D-M behavior.

The spatial decision heuristics can be identified by calculating the route length along which items need to be carried given some sequence of destinations. Ideally, one should weight each segment of the trip with the carrying weight of the bought items, but because such data were not available, only the route length was measured. To determine whether a pedestrian applied the N-D-O heuristic or the F-D-O heuristic, the following formulas were used:

$$
\begin{array}{ll}
D_{1}=\Sigma_{i} d_{n i}, & i=1, \ldots, N^{\prime} \text { and } \\
D_{2}=\Sigma_{i} d_{i x}, & i=N^{\prime \prime}, \ldots, N,
\end{array}
$$

where $N$ is the number of stops;

$N^{\prime}=\operatorname{INT}[(N+1) / 2],[\operatorname{INT}(x)$ : convert $x$ to integer $] ;$

$N^{\prime \prime}=N-N^{\prime}+1$;

$d_{n i}$ is the distance traveled from entry point $n$ to destination $i$; and

$d_{i x}$ is the distance traveled from destination $i$ to exit point $x$.

Pedestrians were said to apply the $\mathrm{N}-\mathrm{D}-\mathrm{O}$ heuristic if the ratio $D_{1} / D_{2}$ was less than 1.0. If this ratio was greater than 1.0 , the pedestrian was said to display the F-D-O heuristic.

Some of the research questions necessitate a distinction between planned and unplanned trips. We classified a trip as "planned" if the respondent had planned to visit all chosen destinations; otherwise the trip was "unplanned." All of the analyses, however, were based on only those destinations that the respondent planned to visit before entering the city center, regardless of whether we classified the trip as "planned" or "unplanned."

\section{The Use of Different Temporal Decision Heuristics}

Table 2 summarizes the frequency with which different temporal decision heuristics are used in the two cities. It demonstrates that the global-distanceminimizing heuristic is used most frequently (40 percent in Maastricht and 55 percent in Eindhoven). This percentage is higher for Eindhoven probably because 
TABLE 5. Association between Temporal Heuristics and Number of Stops

\begin{tabular}{|c|c|c|c|c|c|c|}
\hline \multirow[b]{2}{*}{ Heuristic } & \multicolumn{3}{|c|}{ Planned } & \multicolumn{3}{|c|}{ Unplanned } \\
\hline & $3^{a}$ & 4 & $5+$ & 3 & 4 & $5+$ \\
\hline $\begin{array}{l}\text { L-D-M } \\
\text { T-D-M } \\
\text { G-D-M } \\
\text { Other }\end{array}$ & $\begin{array}{c}2.6^{\mathrm{b}} \\
14.2 \\
45.7 \\
37.5\end{array}$ & $\begin{array}{r}7.4 \\
12.6 \\
34.4 \\
45.4\end{array}$ & $\begin{array}{c}\text { MA } \\
9.5 \\
7.1 \\
20.2 \\
63.1\end{array}$ & $\begin{array}{l}\text { HT } \\
\overline{1.9} \\
59.1 \\
39.0\end{array}$ & $\begin{array}{r}9.1 \\
6.5 \\
32.5 \\
51.9\end{array}$ & $\begin{array}{r}2.9 \\
22.1 \\
75.0\end{array}$ \\
\hline Total & 100.0 & 100.0 & 100.0 & 100.0 & 100.0 & 100.0 \\
\hline $\begin{array}{l}\text { L-D-M } \\
\text { T-D-M } \\
\text { G-D-M } \\
\text { Other }\end{array}$ & $\begin{array}{r}5.2 \\
24.6 \\
53.2 \\
17.0\end{array}$ & $\begin{array}{r}8.7 \\
21.7 \\
46.4 \\
23.2\end{array}$ & $\begin{array}{r}\text { EIN } \\
8.6 \\
10.0 \\
52.9 \\
28.6\end{array}$ & $\begin{array}{r}\text { EN } \\
2.1 \\
8.3 \\
66.7 \\
22.9\end{array}$ & $\begin{array}{r}\overline{11.0} \\
54.8 \\
34.2\end{array}$ & $\begin{array}{r}3.6 \\
10.9 \\
52.7 \\
32.7\end{array}$ \\
\hline Total & 100.0 & 100.0 & 100.0 & 100.0 & 100.0 & 100.0 \\
\hline
\end{tabular}

${ }^{2} 3,4$, and $5+$ are number of stops per trip.

${ }^{\mathrm{b}}$ Values are given as percentages.

of its less-complex structure. Only approximately 4 percent of the respondents in both cities reveal a local-distance-minimizing heuristic. This implies that the decision-making process of a substantial number of pedestrians is not uncovered by the assumption of shortest-route behavior underlying almost all existing models of pedestrian movement, even if it is remembered that the shortestroute assumption applies also to the T-D-M heuristic.

Table 2 also shows that the percentages of respondents revealing local- or total-distance-minimizing behavior are significantly lower for unplanned trips than for planned trips. Thus, it appears that pedestrians who go to downtown retailing environments with a list of shops to visit are engaged in a rational decision-making process in the sense that their sequencing of shop visits and/or route-choice behavior between successive stops is more optimal.

\section{The Use of Different Spatial Decision Heuristics}

Table 3 presents the results of the analysis conducted to examine the use of spatial heuristics. It demonstrates that the farthest-distance-oriented heuristic is used most in Maastricht. This finding suggests that a majority of the pedestrians in Maastricht first visit shops located farther from the point where they entered the city center and then proceed back to their point of departure. Although we could not test this empirically in the present study, such behavior might be explained by the fact that pedestrians would have to carry their heavy purchases across smaller distances. Table 3, however, also demonstrates that the pedestrians in Eindhoven apply the nearest-destination-oriented heuristic most. It is not readily evident why these differences occur.

Finally, Table 3 shows that the percentage of respondents applying a nearestdistance-oriented heuristic is higher for unplanned trips than for planned trips in both cities. This finding is consistent with our theoretical expectations. Pedestrians who plan their visits have a higher probability of revealing optimal behavior in terms of the sequence in which these shops are visited. Likewise, sequencing behavior of pedestrians who do not plan their trips is more likely a function of routing considerations. 
TABLE 6. Results of the Loglinear Analysis - Temporal Heuristics Factor

\begin{tabular}{|c|c|c|}
\hline Coeff. & Std. Err. & $t$-Value \\
\hline 2.68949 & 0.12230 & 21.9911 \\
\hline $\begin{array}{r}-0.02600 \\
0.02600\end{array}$ & $\begin{array}{l}0.12230 \\
0.12230\end{array}$ & $\begin{array}{r}-0.21263 \\
0.21263\end{array}$ \\
\hline $\begin{array}{r}0.32318 \\
-0.32318\end{array}$ & $\begin{array}{l}0.12230 \\
0.12230\end{array}$ & $\begin{array}{r}2.64253 \\
-2.64253\end{array}$ \\
\hline $\begin{array}{r}-1.35741 \\
-0.58038 \\
1.05140 \\
0.88639\end{array}$ & $\begin{array}{l}0.30409 \\
0.23358 \\
0.12716 \\
0.12762\end{array}$ & $\begin{array}{r}-4.46389 \\
-2.48472 \\
8.26811 \\
6.94550\end{array}$ \\
\hline $\begin{array}{r}0.39010 \\
-0.01258 \\
-0.37753\end{array}$ & $\begin{array}{l}0.17194 \\
0.17167 \\
0.17525\end{array}$ & $\begin{array}{r}2.26889 \\
-0.07326 \\
-2.15428\end{array}$ \\
\hline $\begin{array}{r}-0.08091 \\
0.08091 \\
0.08091 \\
-0.08091\end{array}$ & $\begin{array}{l}0.12230 \\
0.12230 \\
0.12230 \\
0.12230\end{array}$ & $\begin{array}{r}-0.66161 \\
0.66161 \\
0.66161 \\
-0.66161\end{array}$ \\
\hline $\begin{array}{r}-0.10455 \\
0.37197 \\
0.15512 \\
-0.42254 \\
0.10455 \\
-0.37197 \\
-0.15512 \\
0.42254\end{array}$ & $\begin{array}{l}0.30409 \\
0.23358 \\
0.12716 \\
0.12762 \\
0.30409 \\
0.23358 \\
0.12716 \\
0.12762\end{array}$ & $\begin{array}{r}-0.34381 \\
1.59248 \\
1.21986 \\
-3.31095 \\
0.34381 \\
-1.59248 \\
-1.21986 \\
3.31095\end{array}$ \\
\hline $\begin{array}{r}0.08400 \\
-0.13937 \\
0.05537 \\
-0.08400 \\
0.13937 \\
-0.05537\end{array}$ & $\begin{array}{l}0.17194 \\
0.17167 \\
0.17525 \\
0.17194 \\
0.17167 \\
0.17525\end{array}$ & $\begin{array}{r}0.48855 \\
-0.81187 \\
0.31597 \\
-0.48855 \\
0.81187 \\
-0.31597\end{array}$ \\
\hline $\begin{array}{r}0.28006 \\
0.28570 \\
-0.26064 \\
-0.30512 \\
-0.28006 \\
-0.28570 \\
0.26064 \\
0.30512\end{array}$ & $\begin{array}{l}0.30409 \\
0.23358 \\
0.12716 \\
0.12762 \\
0.30409 \\
0.23358 \\
0.12716 \\
0.12762\end{array}$ & $\begin{array}{r}0.92097 \\
1.22315 \\
-2.04965 \\
-2.39082 \\
-0.92097 \\
-1.22315 \\
2.04965 \\
2.39082\end{array}$ \\
\hline $\begin{array}{r}0.11596 \\
-0.09775 \\
-0.01821 \\
-0.11596 \\
0.09775 \\
0.01821\end{array}$ & $\begin{array}{l}0.17194 \\
0.17167 \\
0.17525 \\
0.17194 \\
0.17167 \\
0.17525\end{array}$ & $\begin{array}{r}0.67441 \\
-0.56941 \\
-0.10390 \\
-0.67441 \\
0.56941 \\
0.10390\end{array}$ \\
\hline $\begin{array}{r}-0.54060 \\
0.20462 \\
0.33598 \\
0.21926 \\
0.13172 \\
-0.35098 \\
0.43020 \\
-0.19639 \\
-0.23381 \\
-0.10886 \\
-0.13995 \\
0.24881\end{array}$ & $\begin{array}{l}0.46648 \\
0.46425 \\
0.34882 \\
0.27215 \\
0.27175 \\
0.42360 \\
0.17667 \\
0.17872 \\
0.18404 \\
0.17849 \\
0.17978 \\
0.18314\end{array}$ & $\begin{array}{r}-1.15890 \\
0.44075 \\
0.96319 \\
0.80566 \\
0.48471 \\
-0.82857 \\
2.43512 \\
-1.09891 \\
-1.27041 \\
-0.60991 \\
-0.77843 \\
1.35857\end{array}$ \\
\hline
\end{tabular}

A : City

Maastricht

2 Eindhoven

B : Kind of Trip

1 Planned

2 Unplanned

C: Heuristic

1 L-D-M

T-D-M

G-D-M

4 Other

D : Number of Stops

13 Stops

24 Stops

5 Stops or More

$\mathrm{AB}$

11

2

1

22

$\mathrm{AC}$

1

2

2

3

24

AD

1

12

3

21

$\begin{array}{ll}2 & 3\end{array}$

1

2

3

$\begin{array}{ll}1 & 4 \\ 2 & 1\end{array}$

2

3

2

$\mathrm{BD}$

11

12

13

21

$\begin{array}{ll}2 & 2 \\ 2 & 3\end{array}$

CD

11

12

13

21

$\begin{array}{ll}2 & 2\end{array}$

23

$\begin{array}{ll}3 & 1\end{array}$

32

$\begin{array}{ll}3 & 3\end{array}$

41

42

43

(a)

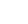

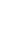

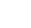

3

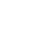

(

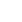

4

3

4

2

.21263

64253

64253

26811

94550

26889

0.66161

0.66161

0.66161

0.34381

1.59248

(1)

34381

.59248

1.21986

0.81187

0.31597

0.92097

1.22315

$-2.04965$

(39082

1.22315

2.04965

0.56941

0.10390

67441

0.56941
0.10390

1.15890

0.44075

80566

0.48471

(8)

1.09891

$-1.27041$

$-0.77843$ 
TABLE 6. Continued

Factor

$\mathrm{ABC}$

$\begin{array}{lll}1 & 1 & 1\end{array}$

$\begin{array}{lll}1 & 1 & 2\end{array}$

$\begin{array}{lll}1 & 1 & 3\end{array}$

$\begin{array}{lll}1 & 1 & 4\end{array}$

$\begin{array}{lll}1 & 2 & 1\end{array}$

122

123

124

$\begin{array}{lll}2 & 1 & 1\end{array}$

$\begin{array}{lll}2 & 1 & 2\end{array}$

$\begin{array}{lll}2 & 1 & 3\end{array}$

$\begin{array}{lll}2 & 1 & 4\end{array}$

$\begin{array}{lll}2 & 2 & 1\end{array}$

$\begin{array}{lll}2 & 2 & 2\end{array}$

$\begin{array}{lll}2 & 2 & 3\end{array}$

ABD

$\begin{array}{lll}1 & 1 & 1\end{array}$

$\begin{array}{lll}1 & 1 & 2\end{array}$

$\begin{array}{lll}1 & 1 & 3\end{array}$

$\begin{array}{lll}1 & 2 & 1\end{array}$

$\begin{array}{lll}1 & 2 & 2\end{array}$

$\begin{array}{lll}1 & 2 & 3\end{array}$

$\begin{array}{lll}2 & 1 & 1\end{array}$

$\begin{array}{lll}2 & 1 & 2\end{array}$

$\begin{array}{lll}2 & 1 & 3\end{array}$

$\begin{array}{lll}2 & 2 & 1\end{array}$

$\begin{array}{lll}2 & 2 & 2\end{array}$

22

$\mathrm{ACD}$

$\begin{array}{lll}1 & 1 & 1 \\ 1 & 1 & 2\end{array}$

$\begin{array}{lll}1 & 1 & 3\end{array}$

$\begin{array}{lll}1 & 2 & 1\end{array}$

122

123

131

$\begin{array}{lll}1 & 3 & 2\end{array}$

133

$\begin{array}{lll}1 & 4 & 1\end{array}$

$\begin{array}{lll}1 & 4 & 2\end{array}$

143

$\begin{array}{lll}2 & 1 & 1\end{array}$

$\begin{array}{lll}2 & 1 & 2\end{array}$

$\begin{array}{lll}2 & 1 & 3\end{array}$

$\begin{array}{lll}2 & 2 & 1\end{array}$

$\begin{array}{lll}2 & 2 & 2\end{array}$

$\begin{array}{lll}2 & 2 & 3\end{array}$

$\begin{array}{lll}2 & 3 & 1\end{array}$

$\begin{array}{lll}2 & 3 & 2\end{array}$

$\begin{array}{lll}2 & 3 & 3\end{array}$

$\begin{array}{lll}2 & 4 & 1\end{array}$

$\begin{array}{lll}2 & 4 & 2 \\ 2 & 4 & 3\end{array}$

$$
\text { Coeff. }
$$

0.16068

$-0.16425$

0.02305

$-0.01949$

$-0.16068$

0.16425

$-0.02305$

0.01949

$-0.16068$

0.16425

$-0.02305$

0.01949

0.16068

$-0.16425$

0.02305

$-0.01949$

$-0.01302$

$-0.05263$

0.06566

0.01302

0.05263

$-0.06566$

0.01302

0.05263

$-0.06566$

$-0.01302$

$-0.05263$

0.06566

0.34176

$-0.22222$

$-0.11954$

$-0.04458$

$-0.00808$

0.05266

$-0.23744$

0.06075

0.17669

$-0.05974$

0.16955

$-0.10981$

$-0.34176$

0.22222

0.11954

0.04458

0.00808

$-0.05266$

0.23744

$-0.06075$

$-0.17669$

0.05974

$-0.16955$

0.10981
Std. Err.

0.30409

0.23358

0.12716

0.12762

0.30409

0.23358

0.12716

0.12762

0.30409

0.23358

0.12716

0.12762

0.30409

0.23358

0.12716

0.12762

0.17194

0.17167

0.17525

0.17194

0.17167

0.17525

0.17194

0.17167

0.17525

0.17194

0.17167

0.17525

0.46648

0.46425

0.34882

0.27215

0.27175

0.42360

0.17667

0.17872

0.18404

0.17849

0.17978

0.18314

0.46648

0.46425

0.34882

0.27215

0.27175

0.42360

0.17667

0.17872

0.18404

0.17849

0.17978

0.18314
t-Value

0.52841

$-0.70318$

0.18127

$-0.15270$

$-0.52841$

0.70318

$-0.18127$

0.15270

$-0.52841$

0.70318

$-0.18127$

0.15270

0.52841

$-0.70318$

0.18127

$-0.15270$

$-0.07575$

$-0.30659$

0.37465

0.07575

0.30659

$-0.37465$

0.07575

0.30659

$-0.37465$

$-0.07575$

$-0.30659$

0.37465

0.73263

$-0.47866$

$-0.34269$

$-0.16379$

$-0.02973$

0.12430

$-1.34402$

0.33992

0.96006

$-0.33468$

0.94309

$-0.59959$

$-0.73263$

0.47866

0.34269

0.16379

0.02973

$-0.12430$

1.34402

$-0.33992$

$-0.96006$

0.33468

$-0.94309$

0.59959 


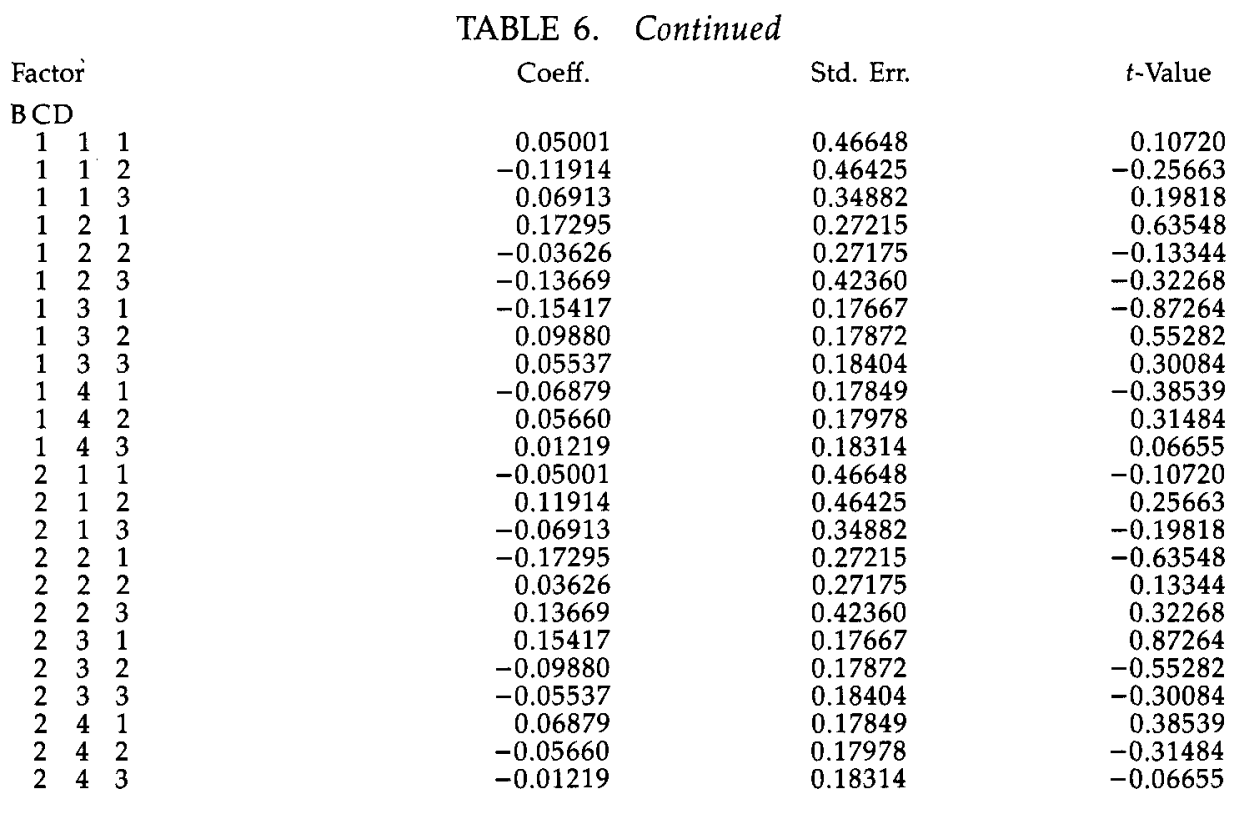

Associations between Spatial and Temporal Heuristics

Table 4 summarizes the associations between the temporal and spatial heuristics. For example, for the case of planned trips in Maastricht, the F-D-O heuristic is relatively more associated with either a L-D-M or T-D-M heuristic than with a G-D-M heuristic. The data also demonstrate that this association disappears for unplanned trips. These findings, however, are not substantiated by the results obtained for Eindhoven. In the case of planned trips, the spatial heuristics are largely independent from the temporal heuristics.

A possible explanation for these results might be that the complexity of the retail environment affects pedestrians' propensity to plan a shopping trip. Pedestrians in Maastricht who plan a trip a priori are more likely to reveal optimal behavior as exemplified by a higher probability of applying both T-D-M and F-D-O heuristics.

\section{Correlates of Temporal and Spatial Heuristics}

One might expect that the use of temporal heuristics is influenced by the complexity of the journey as indicated by the number of stops made during the journey. The more stops to be made, the more difficult it will be to reveal rational, optimizing behavior. To test this hypothesis, the use of the various temporal heuristics was crossed against the number of stops made during the shopping trip. Again, the results were disaggregated according to whether the trip was planned or not, and the analysis was performed for each of the two cities separately.

The results, given in Table 5, illustrate that the propensity to adopt a localdistance-minimizing heuristic increases with an increasing number of stops made during the journey for planned trips in Maastricht. The same tendency is observed for Eindhoven, although it seems that in this case saturation already 
TABLE 7. Association between Spatial Heuristics and Number of Stops

\begin{tabular}{|c|c|c|c|c|c|c|}
\hline \multirow[b]{2}{*}{ Heuristic } & \multicolumn{3}{|c|}{ Planned } & \multicolumn{3}{|c|}{ Unplanned } \\
\hline & $3^{\mathrm{a}}$ & 4 & $5+$ & 3 & 4 & $5+$ \\
\hline & \multicolumn{6}{|c|}{ MAASTRICHT } \\
\hline $\begin{array}{l}\text { N-D-O } \\
\text { F-D-O } \\
\text { Neutral }\end{array}$ & $\begin{array}{c}24.6^{\mathrm{b}} \\
67.4 \\
8.0\end{array}$ & $\begin{array}{r}21.0 \\
73.9 \\
5.1\end{array}$ & $\begin{array}{l}20.2 \\
69.0 \\
10.7\end{array}$ & $\begin{array}{r}25.3 \\
6.2 \\
8.5\end{array}$ & $\begin{array}{r}31.2 \\
61.0 \\
7.8\end{array}$ & $\begin{array}{l}29.4 \\
57.4 \\
13.2\end{array}$ \\
\hline \multirow[t]{2}{*}{ Total } & 100.0 & 100.0 & 100.0 & 100.0 & 100.0 & 100.0 \\
\hline & \multicolumn{6}{|c|}{ EINDHOVEN } \\
\hline $\begin{array}{l}\text { N-D-O } \\
\text { F-D-O } \\
\text { Neutral }\end{array}$ & $\begin{array}{r}46.8 \\
46.2 \\
7.0\end{array}$ & $\begin{array}{l}47.8 \\
40.6 \\
11.6\end{array}$ & $\begin{array}{l}50.0 \\
38.6 \\
11.4\end{array}$ & $\begin{array}{r}47.9 \\
44.4 \\
7.7\end{array}$ & $\begin{array}{r}54.8 \\
42.5 \\
2.7\end{array}$ & $\begin{array}{l}61.8 \\
25.5 \\
12.7\end{array}$ \\
\hline Total & 100.0 & 100.0 & 100.0 & 100.0 & 100.0 & 100.0 \\
\hline
\end{tabular}

occurs after four stops. As expected, the use of the total-distance-minimizing heuristic decreases monotonically with an increasing number of stops in both cities. The data in Table 4 suggest that the tendency to adopt a T-D-M heuristic drops dramatically for more than four stops. In the case of Maastricht, the use of a G-D-M heuristic also drops with an increasing number of stops made during the trip. This result is not obtained for Eindhoven; there the percentage of respondents applying a G-D-M heuristic is more or less independent of the number of stops. Again, this result might be due to the less complicated layout of the shopping environment in Eindhoven, which could result in pedestrians having a more reliable cognitive image of the structure of the downtown shopping area.

If we examine the results obtained for the unplanned trips, few regularities can be found. The use of a global-distance-minimizing heuristic seems to drop more dramatically with an increasing number of stops as compared to planned trips. Perhaps most significant, though, is the relatively high number of respondents that apply some "other" heuristic, and this number increases with an increasing number of stops made during the journey, especially in Maastricht.

To gain more insight into the relationships between the use of the identified temporal heuristics and the city, the nature of the trip, and the number of stops, a loglinear analysis was performed on the data summarized in Table 5. Use of a temporal heuristic served as the dependent variable of the analysis. The results of the loglinear analysis are presented in Table 6. Only the following coefficients were significant beyond the 5 percent probability level. First, the results of the loglinear analysis demonstrated a significant difference in the use of the "other" heuristic between the two cities. Second, the results suggested that the percentage of respondents applying a G-D-M or "other" heuristic was significantly less for planned trips as compared to unplanned trips. Finally, the two-way interaction effect between G-D-M and three stops was significant, suggesting that the propensity to adopt a global-distance-minimizing heuristic was higher when only three stops were made during the journey. The latter result supports our contention that pedestrians reveal less rational, optimizing behavior with in- 
TABLE 8. Results of the Loglinear Analysis - Spatial Heuristics

Factor

$\begin{array}{rl}\text { A : } & \text { City } \\ 1 & \text { Maastricht } \\ 2 & \text { Eindhoven } \\ \text { B: } & \text { Kind of Trip } \\ 1 & \text { Planned } \\ 2 & \text { Unplanned } \\ \text { C: } & \text { Heuristics } \\ 1 & \text { F-D-O } \\ 2 & \text { N-D-O } \\ 3 & \text { Neutral } \\ \text { D: } & \text { Number of Stops } \\ 1 & 3 \text { Stops } \\ 2 & 4 \text { Stops } \\ 3 & 5 \text { Stops or More }\end{array}$

2

1

22

AC

11

12

13

$\begin{array}{ll}2 & 1\end{array}$

22

23

AD

11

12

13

$\begin{array}{ll}2 & 1\end{array}$

2

$\mathrm{BC}$

11

12

13

21

2

BD

11

12

13

21

$\begin{array}{ll}2 & 2 \\ & 3\end{array}$

D

11

12

13

21

22

23

$\begin{array}{ll}3 & 1\end{array}$

$\begin{array}{ll}3 & 2\end{array}$

33
Coeff.

3.20133

$-0.08087$

0.08087

0.11856

$-0.11856$

0.71535

0.36607

$-1.08143$

0.54233

$-0.25614$

$-0.28619$

$-0.01528$

0.01528

0.01528

$-0.01528$

$-0.29187$

0.32619

$-0.03431$

0.29187

$-0.32619$

0.03431

0.00594

$-0.01335$

0.00741

$-0.00594$

0.01335

$-0.00741$

0.06733

$-0.09830$

0.03096

$-0.06733$

0.09830

$-0.03096$

0.01902

0.01490

$-0.03392$

$-0.01902$

$-0.01490$

0.03392

0.09137

0.11925

$-0.21062$

$-0.02813$

0.08230

$-0.05417$

$-0.06325$

$-0.20155$

0.26479
Std. Err.

0.04324

0.04324

0.04324

0.04324

0.04324

0.05055

0.05230

0.07698

0.05327

0.06810

0.06116

0.04324

0.04324

0.04324

0.04324

0.05055

0.05230

0.07698

0.05055

0.05230

0.07698

0.05327

0.06810

0.06116

0.05327

0.06810

0.06116

0.05055

0.05230

0.07698

0.05055

0.05230

0.07698

0.05327

0.06810

0.06116

0.05327

0.06810

0.06116

0.06191

0.07761

0.07401

0.06474

0.08034

0.07592

0.09489

0.12389

0.10583
$t$-Value

74.0440

$-1.87047$

1.87047

2.74223

$-2.74223$

14.1507

6.99996

$-14.0489$

10.1803

$-3.76126$

$-4.67956$

$-0.35340$

0.35340

0.35340

$-0.35340$

$-5.77368$

6.23724

$-0.44576$

5.77368

$-6.23724$

0.44576

0.11152

$-0.19610$

0.12121

$-0.11152$

0.19610

$-0.12121$

1.33194

$-1.87960$

0.40225

$-1.33194$

1.87960

$-0.40225$

0.35701

0.21881

$-0.55464$

$-0.35701$

$-0.21881$

0.55464

1.47585

1.53660

$-2.84587$

$-0.43449$

1.02440

$-0.71351$

$-0.66654$

$-1.62683$

2.50212 
TABLE 8. Continued

Factor

$\mathrm{ABC}$

$\begin{array}{lll}1 & 1 & 1 \\ 1 & 1 & 2 \\ 1 & 1 & 3 \\ 1 & 2 & 1 \\ 1 & 2 & 2 \\ 1 & 2 & 3 \\ 2 & 1 & 1 \\ 2 & 1 & 2 \\ 2 & 1 & 3 \\ 2 & 2 & 1 \\ 2 & 2 & 2 \\ 2 & 2 & 3\end{array}$

$\mathrm{ABD}$

$\begin{array}{lll}1 & 1 & 1\end{array}$

$\begin{array}{lll}1 & 1 & 2\end{array}$

$\begin{array}{lll}1 & 1 & 3\end{array}$

$\begin{array}{lll}1 & 2 & 1\end{array}$

$\begin{array}{lll}1 & 2 & 2\end{array}$

123

$\begin{array}{lll}2 & 1 & 1\end{array}$

$\begin{array}{lll}2 & 1 & 2\end{array}$

$\begin{array}{lll}2 & 1 & 3\end{array}$

$\begin{array}{lll}2 & 2 & 1\end{array}$

$\begin{array}{lll}2 & 2 & 2\end{array}$

$\begin{array}{lll}2 & 2 & 3\end{array}$

ACD

$\begin{array}{lll}1 & 1 & 1\end{array}$

$\begin{array}{lll}1 & 1 & 2\end{array}$

$\begin{array}{lll}1 & 1 & 3\end{array}$

121

122

$\begin{array}{lll}1 & 2 & 3\end{array}$

$\begin{array}{lll}1 & 3 & 1\end{array}$

$\begin{array}{lll}1 & 3 & 2\end{array}$

$\begin{array}{lll}1 & 3 & 3\end{array}$

$\begin{array}{lll}2 & 1 & 1\end{array}$

$\begin{array}{lll}2 & 1 & 2\end{array}$

$\begin{array}{lll}2 & 1 & 3\end{array}$

$\begin{array}{lll}2 & 2 & 1\end{array}$

$\begin{array}{lll}2 & 2 & 2\end{array}$

$\begin{array}{lll}2 & 2 & 3\end{array}$

$\begin{array}{lll}2 & 3 & 1\end{array}$

$\begin{array}{lll}2 & 3 & 2\end{array}$

$\begin{array}{lll}2 & 3 & 3\end{array}$

BCD

111

112

$\begin{array}{lll}1 & 1 & 3\end{array}$

121

122

123

$\begin{array}{lll}1 & 3 & 1\end{array}$

132

133

$\begin{array}{lll}2 & 1 & 1\end{array}$

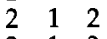

$\begin{array}{lll}2 & 1 & 3\end{array}$

$\begin{array}{lll}2 & 2 & 1\end{array}$

$\begin{array}{lll}2 & 2 & 2\end{array}$

$\begin{array}{lll}2 & 2 & 3\end{array}$

$\begin{array}{lll}2 & 3 & 1\end{array}$

$\begin{array}{lll}2 & 3 & 2 \\ 2 & 3 & 3\end{array}$
Coeff.

-0.03725
-0.01054
0.04779
0.03725
0.01054
-0.04779
0.03725
0.01054
-0.04779
-0.03725
-0.01054
0.04779

$-0.02071$

$-0.06281$

0.08352

0.02071

0.06281

$-0.08352$

0.02071

0.06281

$-0.08352$

$-0.02071$

$-0.06281$

0.08352

0.08289

$-0.01009$

$-0.07279$

$-0.02548$

$-0.03548$

0.06096

$-0.05740$

0.04557

0.01183

$-0.08289$

0.01009

0.07279

0.02548

0.03548

$-0.06096$

0.05740

$-0.04557$

$-0.01183$

$-0.05133$

$-0.04564$

0.09697

0.08996

$-0.06724$

$-0.02273$

$-0.03863$

0.11287

$-0.07424$

0.05133

0.04564

$-0.09697$

$-0.08996$

0.06724

0.02273

0.03863

$-0.11287$

0.07424
Std. Err.

0.05055

0.05230

0.07698

0.05055

0.05230

0.07698

0.05055

0.05230

0.07698

0.05055

0.05230

0.07698

0.05327

0.06810

0.06116

0.05327

0.06810

0.06116

0.05327

0.06810

0.06116

0.05327

0.06810

0.06116

0.06191

0.07761

0.07401

0.06474

0.08034

0.07592

0.09489

0.12389

0.10583

0.06191

0.07761

0.07401

0.06474

0.08034

0.07592

0.09489

0.12389

0.10583

0.06191

0.07761

0.07401

0.06474

0.08034

0.07592

0.09489

0.12389

0.10583

0.06191

0.07761

0.07401

0.06474

0.08034

0.07592

0.09489

0.12389

0.10583
$t$-Value

-0.73687
-0.20150
0.62082
0.73687
0.20150
-0.62082
0.73687
0.20150
-0.62082
-0.73687
-0.20150
0.62082

$-0.38867$

$-0.92236$

1.36564

0.38867

0.92236

$-1.36564$

0.38867

0.92236

$-1.36564$

$-0.38867$

$-0.92236$

1.36564

1.33875

$-0.13004$

$-0.98357$

$-0.39364$

$-0.44158$

0.80292

$-0.60496$

0.36782

0.11183

$-1.33875$

0.13004

0.98357

0.39364

0.44158

$-0.80292$

0.60496

$-0.36782$

$-0.11183$

$-0.82912$

$-0.58808$

1.31025

1.38964

$-0.83689$

$-0.29934$

$-0.40710$

0.91108

$-0.70156$

0.82912

0.58808

$-1.31025$

$-1.38964$

0.83689

0.29934

0.40710

$-0.91108$

0.70156 
creasing complexity, as indicated by an increasing number of stops, of their journey.

A similar analysis was performed with respect to the use of the spatial heuristics. The results of this analysis are presented in Table 7. They indicate that in the case of planned trips in the city of Maastricht, the use of the N-D-O heuristic tended to decrease slightly as the number of stops increased. This was compensated first by an increasing percentage of pedestrians applying the F-D-O heuristic in the case of four stops, and second by relatively more pedestrians using a "neutral" heuristic in the case of five stops. Eindhoven displayed reverse results. The percentage of respondents applying a nearestdestination-oriented heuristic slightly increased with an increasing number of stops. As a result the percentage for the F-D-O heuristic monotonically decreased with an increasing number of stops. It is difficult to think of facts that might explain these observed differences between the two cities. In the case of unplanned trips, the percentage of pedestrians applying the F-D-O heuristic decreased with an increasing number of stops in both cities, while the percentage of pedestrians applying the N-D-O heuristic tended to increase with an increasing number of stops made during the journey. This finding is consistent with our theoretical expectations in that one would expect pedestrians to patronize shops relatively more in order of appearance with an increasing complexity of the trip since the trip was not planned a priori.

As in the case of the temporal heuristics, a loglinear analysis was performed on the four-dimensional contingency table (Table 8). The results of the loglinear analysis showed significant differences in the use of the two spatial heuristics between Maastricht and Eindhoven. In addition, the analysis revealed a significant two-way interaction effect between the use of the F-D-O heuristic and five or more stops, suggesting that pedestrians were less inclined to use a F-D$O$ heuristic when their shopping trip involved five or more stops. A significant effect indicated that in this case they tended to use more the neutral heuristic.

\section{DISCUSSION AND CONCLUSIONS}

The present study is part of a wider research project that seeks to develop and test a simulation model of shopping pedestrians' destination- and routechoice behavior in city centers. Most of the existing models (e.g., Borgers and Timmermans 1986a, 1986b; Hagishima, Mitsuyoshi, and Kurose 1987) typically assume that shopping pedestrians are engaged in a sequential decision-making process: given a sequence of destinations to be visited, pedestrians are assumed to minimize distance between all successive pairs of destinations during their shopping trip. The present empirical analysis has demonstrated that such a distance-minimizing strategy is only one of various possible decision heuristics pedestrians may apply. The research findings suggest that only a small proportion is engaged in distance-minimizing behavior, and this proportion drops with an increasing complexity of the retail environment.

If this result is confirmed in other studies in other cities, it has some important implications for the modeling of pedestrian movement. That is to say, results like the ones obtained in the present study seriously question the validity of assumptions regarding pedestrian destination and, especially, route 
choice behavior that underlie existing models of pedestrian movement. Existing models are only partly based on assumptions that reflect actual pedestrian decision-making and choice processes. Consequently, our ability to predict their destination- and route-choice behavior might be improved if new models that incorporate the heuristics described in the present study were developed. It appears very difficult to incorporate such notions into spatial interaction and discrete choice kinds of framework. Microsimulation approaches look more promising as they allow one to incorporate both qualitative and quantitative assumptions in the model in a straightforward fashion. The authors are currently developing such a model of pedestrian destination- and route-choice behavior.

\section{ACKNOWLEDGMENT}

This project was partly funded by the Dutch Organization for Scientific Research (NWO/SRO).

\section{REFERENCES}

Borgers, A., and Timmermans, H. 1986a. City centre entry points, store location patterns and pedestrian route choice behavior: a microlevel simulation model. Socio-Economic Planning Sciences 20: 25-31.

Borgers, A., and Timmermans, H. 1986b. A model of pedestrian route choice and demand for retail facilities within inner-city shopping areas. Geographical Analysis 18: 115-28.

Gärling, T. 1987. The role of cognitive maps in spatial decisions and choices. Umeà, Sweden: Department of Psychology, University of Umeå, unpublished paper.

Gärling, T., and Gärling, E. 1988. Distance minimizing in downtown pedestrian shopping. Environment and Planning $A$ 20: 547-54.

Gärling, T., Säisä, J., Book, A., and Lindberg, E. 1986. The spatiotemporal sequencing of everyday activities in the large-scale environment. Journal of Environmental Psychology 6: 261-80.

Hagishima, S., Mitsuyoshi, K., and Kurose, S. 1987. Estimation of pedestrian shopping trips in a neighborhood by using a spatial interaction model. Environment and Planning A 19: 1139-53.

Hanson, S. 1979. Urban travel linkages. In Behavioural travel modelling, eds. D. A. Hensher and P. Stopher, pp. 81-100. London: Croom Helm.

Hanson, S. 1980a. The importance of multi-purpose journey to work in urban travel behavior. Transportation 9: 229-48.

Hanson, S. 1980 b. Spatial diversification and multipurpose travel: implications for choice theory. Geographical Analysis 12: 245-57.

Hays-Roth, B., and Hays-Roth, F. 1979. A cognitive model of planning. Cognitive Science 3: 275310.

Hill, M. R. 1984. Stalking the urban pedestrian: a comparison of questionnaire and tracking methodologies for behavioral mapping in large-scale environments. Environment and Behavior 16: 539-50.

O'Kelly, M. E., and Miller, E. J. 1984. Characteristics of multistop multipurpose travel: an empirical study of trip length. Transportation Research Record 976: 33-39.

Säisä, J., and Gärling, G. 1987. Sequential spatial choices in the large-scale environment. Environment and Behavior 19: 614-35.

Shepherd, I. D. H., and Thomas, C. J. 1980. Urban consumer behaviour. In Retail geography, ed. J. A. Dawson, pp. 18-95. London: Croom Helm. 